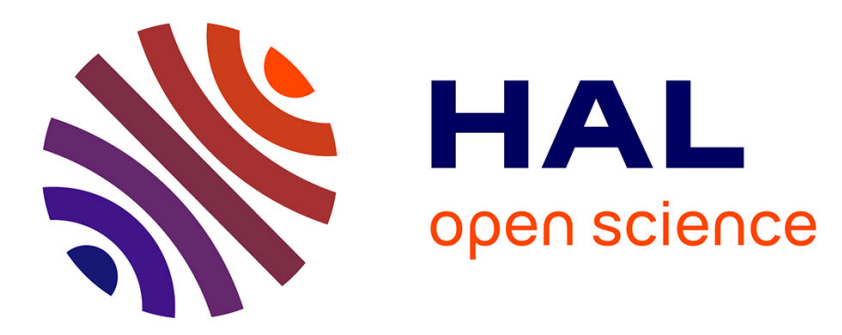

\title{
Removal of diclofenac sodium from aqueous solution by Isabel grape bagasse
}

Márjore Antunes, Valdemar I. Esteves, Régis Guégan, J.S. Crespo, Andreia N. Fernandes, Marcelo Giovanela

\section{- To cite this version:}

Márjore Antunes, Valdemar I. Esteves, Régis Guégan, J.S. Crespo, Andreia N. Fernandes, et al.. Removal of diclofenac sodium from aqueous solution by Isabel grape bagasse. Chemical Engineering Journal, 2012, 192, pp.114-121. 10.1016/j.cej.2012.03.062 . insu-00684443

\section{HAL Id: insu-00684443}

https://hal-insu.archives-ouvertes.fr/insu-00684443

Submitted on 9 May 2012

HAL is a multi-disciplinary open access archive for the deposit and dissemination of scientific research documents, whether they are published or not. The documents may come from teaching and research institutions in France or abroad, or from public or private research centers.
L'archive ouverte pluridisciplinaire HAL, est destinée au dépôt et à la diffusion de documents scientifiques de niveau recherche, publiés ou non, émanant des établissements d'enseignement et de recherche français ou étrangers, des laboratoires publics ou privés. 


\title{
Removal of diclofenac sodium from aqueous solution by Isabel grape bagasse
}

Márjore Antunes $^{\mathrm{a}}$, Valdemar I. Esteves ${ }^{\mathrm{b}}$, Régis Guégan ${ }^{\mathrm{c}}$, Janaina S. Crespo ${ }^{\mathrm{a}}$, Andreia N. Fernandes $^{\mathrm{d}}$, Marcelo Giovanela ${ }^{\mathrm{a}^{*}}$

${ }^{a}$ Centro de Ciências Exatas e Tecnologia, Universidade de Caxias do Sul, 95070-560 Caxias do Sul, RS, Brazil; marjore86@gmail.com; jscrespo@ucs.br; mgiovan1@ucs.br ${ }^{\mathrm{b}}$ CESAM \& Departamento de Química, Universidade de Aveiro, 3810-193 - Aveiro, Portugal; valdemar@ua.pt

'Institut des Sciences de la Terre, CNRS UMR 6113, Université d’Orléans, 45071 Orléans Cedex 2, France; regis.guegan@univ-orleans.fr ${ }^{d}$ Instituto de Química, Universidade Federal do Rio Grande do Sul, 91501-970 - Porto Alegre, RS, Brazil; anfernandes@iq.ufrgs.br

\begin{abstract}
The aim of the present work was to evaluate the morphologic and chemical characteristics of Isabel grape (Vitis labrusca $\mathrm{x}$ Vitis vinifera) bagasse and to describe the adsorption of diclofenac sodium (DCF) from aqueous solutions by this biomass. Grape bagasse was constituted mainly of particles with heterogeneous shapes and sizes, and it exhibited a macroporous structure and a low specific surface area $\left(\sim 2 \mathrm{~m}^{2} \mathrm{~g}^{-1}\right)$.
\end{abstract}

\footnotetext{
* Corresponding author. Tel: + 55543218 2100; Fax: + 555432182159 E-mail address: mgiovan1 @ucs.br (M. Giovanela)
} 
The adsorbent material was also rich in oxygenated functional groups, especially $-\mathrm{OH}$, and required an acidic $\mathrm{pH}$ to neutralize its surface. With respect to the adsorption of DCF, the percentage removal did not appear to depend on the initial concentration of the pharmaceutical. A pseudo-second-order kinetic model described the rate-controlling step, and the adsorption isotherms were well fitted by the Freundlich model. Concerning the thermodynamic data, the results showed that the adsorption of DCF onto grape bagasse occurred via an exothermic process accompanied by a decrease in the randomness at the solid/solution interface. Furthermore, the removal percentages of DCF ranged from 16.4 to $22.8 \%$.

Keywords: Adsorption; Diclofenac sodium; Isabel grape bagasse.

\section{Introduction}

The presence of pharmaceuticals in water bodies has received the attention of many researchers over the past 20 years, mainly due to their incomplete removal during conventional wastewater treatment. The focus on pharmaceuticals has been reflected by the exponential increase in the number of studies of this class of compounds, especially since the 1990s [1-3]. Such studies are related to the detection of these substances in environmental matrices, ecotoxicity tests and processes involving their removal from aqueous media. Thus, pharmaceuticals are currently being considered ubiquitous contaminants in waters, soils and sediments and can be prejudicial to both aquatic biota [4] and to human health [5]. 
Diclofenac sodium (DCF) stands out among the pharmaceuticals that are commonly found in aquatic environments. This substance is a non-steroidal pharmaceutical with anti-inflammatory effects that is commonly used to treat rheumatoid arthritis. The removal percentage of DCF during wastewater treatment processes typically ranges from 21 to $40 \%$ [6], which explains their presence in surface water, groundwater and even in drinking water of different countries [4,7]. DCF is, together with the synthetic hormone $17 \alpha$-ethinylestradiol, one of the few pharmaceutical compounds that has been proven to be ecotoxic, and it affects both aquatic and terrestrial ecosystems [8-10]. In this context, different methods involving membrane filtration, advanced oxidation processes and adsorption with activated carbon [11] have been proposed for the removal of DCF and other pharmaceuticals that are present in aqueous media. However, the implementation of these processes is still not feasible in Brazil due to the high costs associated with them [12]. A promising alternative for the treatment of effluents that contain pharmaceuticals concerns the adsorption processes that utilize agro-industrial wastes as adsorbents as a substitute for activated carbon.

These processes have certain advantages from both economic and environmental points of view, such as availability, abundance, the renewable nature of the adsorbent material, their low cost and easy operation of the treatment plant [13]. However, studies involving the use of this type of biomass in natura for the adsorption of pharmaceuticals are still scarce in the literature. One of the few examples is the recent work of Villaescusa et al. [14] in which grape stalks were used without prior chemical treatment for removing paracetamol from aqueous solutions. 
In the State of Rio Grande do Sul (Brazil), which represents $60.2 \%$ of the total viticulture cultivation area of the country, grape bagasse, a byproduct of the wine industry, is produced on a large scale. In general, this waste is disposed of directly onto the soil of vineyards, mostly by small wineries, instead of adequately treating the waste. This can result in environmental damage, such as a reduction of soil productivity [15] and/or decreasing the concentration of dissolved oxygen in water bodies that receive slurry from the decomposition of the material. Thus, the reuse of grape bagasse in adsorption processes can be a way to help manage solid wastes from wineries.

Therefore, this study aimed to evaluate the morphological and chemical characteristics of Isabel grape (Vitis labrusca $\mathrm{x}$ Vitis vinifera) bagasse and to describe the kinetics, equilibrium and thermodynamics of the adsorption process of DCF using this biomass as an alternative adsorbent.

\section{Materials and methods}

\subsection{Reagents and materials}

Isabel grape bagasse that was generated from the wine production process was collected from the Waldemar Milani Winery (Rio Grande do Sul State, Brazil). The sample was then freeze-dried at $-45^{\circ} \mathrm{C}$ before being crushed and sieved to a particle size less than $150 \mu \mathrm{m}$. After this procedure, the adsorbent was stored in glass bottles and was used without any physical or chemical pre-treatment. All chemicals used in this study were of analytical grade. DCF (Figure 1) $($ CAS number $=15307-79-6$; molecular weight $=$ $318.1 \mathrm{~g} \mathrm{~mol}^{-1}$; chemical formula $=\mathrm{C}_{14} \mathrm{H}_{10} \mathrm{Cl}_{2} \mathrm{NNaO}_{2} ; \mathrm{pK}_{\mathrm{a}}=4.2 ; \log \mathrm{K}_{\mathrm{ow}}=0.57$ ) was 
purchased from Sigma-Aldrich, and it was used without further purification. All solutions were prepared in Milli-Q water.

\subsection{Characterization of grape bagasse}

The grape bagasse sample was sputter-coated with a thin layer of carbon for a few minutes, and the morphology of the biomass was examined by scanning electron microscopy (SEM) using a Philips XL-30 microscope under a 5 kV electron acceleration voltage. Nitrogen adsorption-desorption experiments were performed to obtain information on the grape bagasse specific surface area. They were performed at 77 K using a Quantachrome Nova Surface Area Analyzer instrument. Approximately $120 \mathrm{mg}$ of sample was outgassed at $378 \mathrm{~K}$ for $24 \mathrm{~h}$ under a residual pressure of $0.1 \mathrm{~Pa}$. The data were recorded for relative vapor pressures from 0.013 to $0.0973 \mathrm{~Pa}$. The specific surface area was determined using the Brunauer-Emmett-Teller (BET) equation based on the cross-sectional area of nitrogen $\left(0.162 \mathrm{~nm}^{2}\right)$ at $77 \mathrm{~K}$ [16].

Relative quantities of $\mathrm{C}, \mathrm{H}, \mathrm{N}$ and $\mathrm{S}$ were measured directly with a Carlo Erba 1100 CHNS elemental analyzer. The $\mathrm{O}$ contribution was estimated as the difference between the summed C, H, N and S concentrations and $100 \%$. The semi-quantification of the different types of carbon in the structure of the grape bagasse was performed by integrating the resonance peaks that were present in a solid-state ${ }^{13} \mathrm{C}$ NMR spectrum [17]. The spectrum was obtained with a Bruker AMX $500 \mathrm{MHz}$ Avance spectrometer operating at $11.74 \mathrm{~T}$ and using approximately $100 \mathrm{mg}$ of sample in a $4 \mathrm{~mm}$ rotor. The time between two consecutive pulses was $5 \mathrm{~s}$, and the acquisition was $15 \mathrm{~ms}$. Sample spinning at the magic angle was conducted at a frequency of $9 \mathrm{kHz}$, and a $90^{\circ}$ pulse 
width $(4 \mu \mathrm{s})$ was applied to the protons. The techniques of cross-polarization/magic angle spinning (CP-MAS) were used in all sequences. Each spectrum contained approximately 20,000 transients. The reference at 0 ppm was set using $\operatorname{Si}\left(\mathrm{CH}_{3}\right)_{4}$. The determination of the $\mathrm{pH}$ at which the surface of the grape bagasse was electrically neutral $\left(\mathrm{pH}_{\mathrm{PZC}}\right)$ was performed using the equilibrium method in a batch system that was adapted by Montanher [18]. The experiment consisted of the addition of $20 \mathrm{~mL}$ of a $0.10 \mathrm{~mol} \mathrm{~L}^{-1}$ solution of $\mathrm{NaCl}$ to $200 \mathrm{mg}$ of sample, with $\mathrm{pH}$ values adjusted between 2.0 and 11.0. These adjustments were performed by adding of $0.10 \mathrm{~mol} \mathrm{~L}^{-1}$ solutions of $\mathrm{NaOH}$ or $\mathrm{HCl}$. The suspensions were shaken for $1 \mathrm{~h}$ at $\sim 25^{\circ} \mathrm{C}$ and then filtered; the final $\mathrm{pH}$ was determined with a DM-20 Digimed $\mathrm{pH}$ meter.

\subsection{Adsorption procedure}

The experimental conditions for the adsorption tests were previously optimized by varying the mass of grape bagasse from 2.5 to $10 \mathrm{mg}$, the volume of solution of DCF from 25 to $50 \mathrm{~mL}$, and the stirring speed of the system from 50 to $500 \mathrm{rpm}$. After optimization of these parameters, the adsorption studies were conducted using $5 \mathrm{mg}$ of grape bagasse, $25 \mathrm{~mL}$ of DCF and a stirring speed of $50 \mathrm{rpm}$.

The DCF solutions were used without $\mathrm{pH}$ adjustment $(\mathrm{pH}=5.0)$ and were shielded from light. A blank (grape bagasse and Milli-Q water) was used to eliminate the effect of interferents in the analysis. Aliquots of DCF in mechanical agitation with the grape bagasse were analyzed by molecular absorption spectroscopy in the ultraviolet (UV) region with a Thermo Scientific Evolution 60 spectrophotometer, using a nominal wavelength of $276 \mathrm{~nm}$. The concentration of DCF was obtained between 1 and 
$30 \mathrm{mg} \mathrm{L}^{-1}$ by means of an analytical calibration curve by the method of external standards $\left(r^{2}=0.9999\right)$.

The adsorption capacity of the grape bagasse in a given contact time $\left(q_{t}\right.$, in $\left.\mathrm{mg} \mathrm{g}^{-1}\right)$ and the percentage removal of DCF (\% R) were calculated using Equation (1) and (2), respectively:

$$
\begin{aligned}
& q_{t}=\frac{\left(C_{i}-C_{t}\right) V}{m} \\
& \% R=\left[\left(\frac{C_{i}-C_{e}}{C_{i}}\right) 100\right]-100
\end{aligned}
$$

where $C_{i}, C_{t}$ and $C_{e}$ represent, respectively, the concentrations of $\mathrm{DCF}\left(\mathrm{mg} \mathrm{L}^{-1}\right)$ at the beginning of the experiment, at time $t$ ( $\min$ ) of the adsorption, and the remaining in solution after equilibrium has been reached; $V$ is the volume of the solution to be remedied (L); and $m$ is the mass of grape bagasse $(\mathrm{g})$.

The kinetics and equilibrium of the adsorption process were evaluated using DCF solutions at concentrations of 5, 10, 15, 20 and $30 \mathrm{mg} \mathrm{L}^{-1}$. The tests were performed at $22^{\circ} \mathrm{C}$ and were followed by a period of up to $72 \mathrm{~h}$. The thermodynamic adsorption process, however, was evaluated using DCF solutions with initial concentrations of $10.0 \mathrm{mg} \mathrm{L}^{-1}$. The temperatures of the systems $\left(22,30,42\right.$ and $\left.50^{\circ} \mathrm{C}\right)$ were maintained using a Quimis Q214M ultra-thermostatic bath. These tests were performed for up to $35 \mathrm{~h}$.

\section{Results and discussion}




\subsection{Morphology and surface area of grape bagasse}

The SEM micrograph of the grape bagasse revealed the presence of particles with very heterogeneous shapes and sizes. In addition, the adsorbent was rough and porous. The heterogeneity of the surfaces of these particles may be related to the fact that the material is composed of different parts of the fruit [18]. Moreover, the better visualization of the roughness and porosity of the material in some particles (more than others) was also related to the manner in which it was sampled. The location of the cut from the milling process of the grape bagasse can also influence the view of the roughness of the material because the surface of the particle observed by SEM may represent a cross or longitudinal section of a fiber [19].

The adsorption and desorption isotherms of $\mathrm{N}_{2}$ gas are shown in Figure 2. The behaviors of these isotherms were type II according to the classification of the International Union of Pure and Applied Chemistry (IUPAC) [16] and show an unrestricted monolayer-multilayer adsorption.

In the range of the $\mathrm{P} / \mathrm{P}_{0}$ studied, the profiles of the isotherms were characteristic of nonporous or macroporous adsorbents (pores with diameters greater than $50 \mathrm{~nm}$ ) [16]. Based on the porosity that was observed in the SEM micrograph, the material was considered macroporous [20]. According to Cuerda-Correa et al. [21], the macropores act as transporter pores that allow the adsorbate to diffuse into the adsorbent particles because, in general, organic chemical species such as DCF are barely accessible to micropores.

The specific surface area for the grape bagasse that was determined by the BET method was approximately $2 \mathrm{~m}^{2} \mathrm{~g}^{-1}$, which did not allow the quantification of the volume 
occupied by macropores. This surface area is small compared to other adsorbent materials, such as carbon black (224-1443 $\left.\mathrm{m}^{2} \mathrm{~g}^{-1}\right)$ [21] and activated carbon (659$950 \mathrm{~m}^{2} \mathrm{~g}^{-1}$ ) [22], that have been used to remove pharmaceuticals present in aqueous medium. However, it is superior to other biomass materials, such as rice husk and rice bran (0.69 and $0.46 \mathrm{~m}^{2} \mathrm{~g}^{-1}$, respectively) [23,24].

\subsection{Chemical characterization of grape bagasse}

Similar to other vegetable biomass [25], the grape bagasse showed high levels of carbon (47.70\%) and oxygen (42.70\%) and to a lesser extent hydrogen $(6.80 \%)$ and nitrogen (2.80\%). The solid-state ${ }^{13} \mathrm{C}$ NMR spectrum (result not shown here) was similar to that achieved by Farinella et al. [26].

Concerning the semi-quantification of the main types of carbon that were present in the structure of the adsorbent (Table 1), the material contained a large number of alkyl groups that were substituted with oxygen or nitrogen (67.08\%) (region between 47 and $110 \mathrm{ppm})$, which corroborated the results that were obtained in the elemental analysis. In addition, the fraction of carbons that were bound to hydroxyl groups in the grape bagasse (region between 60 and 95 ppm) surpassed the others groups, which suggested a predominance of carbohydrates, such as cellulose and hemicellulose, in the biomass. The percentage of phenolic structures was lower than that of benzene rings, which indicated that aromatic hydrocarbons predominated over tannins and lignins. Finally, the presence of carbonyl groups (region between 165 and $215 \mathrm{ppm}$ ) was due almost exclusively to the structures of carboxylic acids, esters and amides. 
With respect to the $\mathrm{pH}_{\mathrm{PZC}}$, the results showed that between an initial $\mathrm{pH}$ of 4.0 and 10.0, the grape bagasse behaved as a buffer, maintaining the final $\mathrm{pH}$ approximately 3.59 in all cases. This $\mathrm{pH}$ was considered to be the $\mathrm{pH}$ at which the surface of the adsorbent was electrically neutral [18].

According to the results that were obtained from the characterization analysis, it was possible to infer about the possible functional groups that were present in the grape bagasse that could be influenced by the $\mathrm{pH}$ of the medium [27]: carboxyl $\left(\mathrm{pK}_{\mathrm{a}}=1.7-\right.$ 4.7), hydroxyl $\left(\mathrm{pK}_{\mathrm{a}}=9.5-13.0\right)$, and amino groups $\left(\mathrm{pK}_{\mathrm{a}}=8.0-11.0\right)$. Table 2 presents the equations that represent the possible chemical reactions that occur on the surface of the material that may affect the adsorption of pharmaceuticals, depending on the $\mathrm{pH}$ of the medium.

The influence of $\mathrm{pH}$ on the adsorption of pharmaceuticals with acidic character was evaluated in the work of Cuerda-Correa et al. [21] and Bui and Choi [28]. In both studies, the authors observed that, using a $\mathrm{pH}$ greater than the $\mathrm{pH}_{\mathrm{PZC}}$ values of the adsorbent materials (mesoporous silica SBA-15 and carbon black BP-1300) and the $\mathrm{pK}_{\mathrm{a}}$ values of the drugs that were evaluated (clofibric acid, DCF, ibuprofen, ketoprofen and naproxen), both the adsorbents and the adsorbates had negatively charged surfaces. This resulted in an electrostatic repulsion that hindered the adsorption because the interactions between the solute species and the active sites of the adsorbent under these conditions were weakened, making the adsorption process more reversible.

In the case of grape bagasse, the optimal $\mathrm{pH}$ for the adsorption of pharmaceuticals in its anionic form would be a solution $\mathrm{pH}$ lower than 3.59 because the adsorbent surface would be positively charged and could interact with DCF through electrostatic forces. 
However, at $\mathrm{pH}$ values less than 3.59 and therefore less than the $\mathrm{pK}_{\mathrm{a}}$ of the pharmaceutical $(\mathrm{pKa}=4.20), \mathrm{DCF}$ is in its neutral form, and its solubility in water decreases [29]. Therefore, we chose to work with the solution of the pharmaceutical in its natural $\mathrm{pH}$ in Milli-Q water (approximately 5.0) during the adsorption tests. At this $\mathrm{pH}$, the negative surface charges in grape bagasse were due mainly to the presence of carboxylate anions.

\subsection{Adsorption procedure}

\subsubsection{Effect of contact time and initial concentration of pharmaceutical}

The adsorption of DCF from aqueous solutions onto grape bagasse was performed with five initial concentrations $\left(5,10,15,20\right.$ and $\left.30 \mathrm{mg} \mathrm{L}^{-1}\right)$ using different contact times. In general, the process was faster at the beginning of the experiment, and the maximum adsorption capacity was achieved after several hours of contact time (Figure 3).

Equilibrium was reached after $500 \mathrm{~min}$ for the $5 \mathrm{mg} \mathrm{L}^{-1}$ solution and after 1,400 min for the $10 \mathrm{mg} \mathrm{L}^{-1}$ solution (Figure 3a). For concentrations of 15,20 and $30 \mathrm{mg} \mathrm{L}^{-1}$, equilibrium was reached after 100, 90 and $80 \mathrm{~min}$, respectively (Figure 3b). Moreover, as DCF was transferred to the grape bagasse, the stabilization of the DCF in the solution tended to increase. As a result, it became more difficult to remove the pharmaceutical, possibly due to an increase in the interaction between the DCF and the solvent.

The removal percentages ranged from 16.4 to $22.8 \%$. Thus, the percentage of DCF removal did not appear to depend on the initial concentration of the pharmaceutical because an increase in its concentration did not significantly increase the electrostatic 
repulsion between the anions of DCF and the negatively charged surface of grape bagasse. Similar behavior was obtained by Rossner et al. [30] for the adsorption of sulfamethoxazole onto an Ambersorb 563 resin and a coconut shell-based granular activated carbon. These authors observed that even though the initial concentrations varied by 2.5 orders of magnitude $\left(426 \mathrm{ng} \mathrm{L}^{-1}\right.$ and $\left.100 \mu \mathrm{g} \mathrm{L}^{-1}\right)$, the removal percentage was similar. This was not expected because of the anionic character of the pharmaceutical (i.e., the $\mathrm{pK}_{\mathrm{a}}$ of the sulfonamide group in the structure of the pharmaceutical was 5.60).

\subsubsection{Kinetics of adsorption process}

The adsorption kinetics of DCF onto grape bagasse was evaluated using the linearized pseudo-first-order (Eq. 3) and pseudo-second-order (Eq. 4) equations, represented below [31]:

$$
\begin{aligned}
& \log \left(q_{e}-q_{t}\right)=\log q_{e}-\frac{k_{1}}{2,303} t \\
& \frac{t}{q_{t}}=\frac{1}{k_{2} q_{e}^{2}}+\frac{1}{q_{e}} t
\end{aligned}
$$

where $q_{e}\left(\mathrm{mg} \mathrm{g}^{-1}\right)$ represent the amount of DCF adsorbed at equilibrium and $k_{1}\left(\mathrm{~min}^{-1}\right)$ and $k_{2}\left(\mathrm{mg} \mathrm{g}^{-1} \mathrm{~min}^{-1}\right)$ are the pseudo-first- and pseudo-second-order rate constants, respectively.

The adsorption process followed pseudo-second-order kinetics for all of the concentrations that were tested because the coefficient of determination $\left(r^{2}\right)$ for this model was closest to unity, and, in addition, the theoretical values of $q_{e}$ were similar to 
those that were obtained experimentally (Table 3). This kinetic model assumes that the rate-controlling step depends on the physico-chemical interactions between the adsorbate and the adsorbent surface groups [32].

Moreover, the initial rate $\left(h=h_{2} q_{e}^{2}\right)$ for the adsorption increased with increasing initial concentrations of DCF. This possibly occurs because as the initial concentration of DCF increased, the driving force that caused it to interact with the active sites of the grape bagasse also increased [29].

The values of $q_{e}$ were much higher than those that were reported by Bui and Choi [28], who evaluated the adsorption of DCF by mesoporous silica SBA-15. They found that the highest value of $q_{e}$ was approximately $0.125 \mathrm{mg} \mathrm{g}^{-1}$. This result demonstrated that the grape bagasse exhibits a higher removal capacity of DCF than the ceramic material.

\subsubsection{Diffusion mechanisms}

The kinetic models applied in this study did not permit the identification of the diffusion mechanism involved in the adsorption process. As a result, the external diffusion and the intraparticle diffusion models were tested with the experimental data. The external diffusion process is associated with the initial adsorption rate and can be expressed in its linear form, according to the model proposed by Spahn and Schlunder [29]:

$$
\ln \frac{C_{t}}{C_{i}}=-\beta \frac{S}{V} t
$$

where $\beta$ is the external mass transfer coefficient $\left(\mathrm{m} \mathrm{min}^{-1}\right)$ and $S$ is the specific surface area of the adsorbent material $\left(\mathrm{m}^{2} \mathrm{~g}^{-1}\right)$ estimated by the BET method. In the case of the 
intraparticle diffusion model, the intraparticle diffusion rate constant $\left(\mathrm{k}_{\mathrm{int}}\right)$ can be obtained from the equation proposed by Weber and Morris [23]:

$$
q_{t}=k_{\mathrm{int}} t^{1 / 2}+C
$$

where $C$ represents the thickness of the boundary layer [33]. When the intraparticle diffusion is the limiting stage of the adsorption the graph of $q_{t} v e r s u s t^{1 / 2}$ is a straight line which passes through the origin [34].

With regard to the external diffusion mechanism, it was verified that this model does not provide a satisfactory fit with the experimental data as the coefficient of determination was less than 0.60 for all of the evaluated concentrations and, therefore, these results were not shown here. With respect to the intraparticle diffusion, on the other hand, it was found that the adsorption process presented linear portions that can be assigned to this mechanism (Figure 4). It was evidenced that as the concentration of DCF increases there is an increase in the boundary layer thickness. This is possibly due to the fact that a higher quantity of the pharmaceutical compound dissolved in the water increases the resistance to mass transfer from the adsorbent surroundings [33], because there are more chemical species competing for the macropores of the grape bagasse. None of the intraparticle diffusion plots passed through the origin, indicating that this mechanism is not the limiting step of adsorption.

All of these aspects seem to indicate that the low stirring speed of the system $(50 \mathrm{rpm})$ is the factor that may limit the overall rate of adsorption. However, this stirring speed was required in order to monitor the adsorption process since the interaction between the grape bagasse and the DCF is weak and thus easily broken if the system is vigorously agitated. Moreover, the irregularity in the distribution of macropores in 
grape bagasse, as well as their low specific surface area $\left(2 \mathrm{~m}^{2} \mathrm{~g}^{-1}\right)$ compared with activated carbon (659-950 $\left.\mathrm{m}^{2} \mathrm{~g}^{-1}\right)$ [22], are also factors that may hinder the system from reaching equilibrium more rapidly.

\subsubsection{Desorption process and adsorbent disposal}

The desorption of the DCF was investigated through applying continuous agitation of the system after it reached equilibrium. It was observed that the pharmaceutical compound was completely desorbed from the grape bagasse after $72 \mathrm{~h}$ of contact time for all concentrations studied. This indicates that the process of DCF adsorption by grape bagasse is completely reversible, which increases the lifetime of the adsorbent [21].

The regeneration of bagasse, aimed at its reuse in the adsorption process with a consequent reduction in solid waste generation, can be achieved by washing the grape bagasse under stirring [35]. However, after its reuse in repeated cycles of adsorption / desorption the adsorption capacity of the grape bagasse is expected to decrease. When this occurs, a new sample should be installed and the spent adsorbent can be used as a fertilizer after going through a composting process. In cases where the washing water is rich in DCF, the pharmaceutical compound can be eliminated by applying an advanced oxidation process. In this case, the cost of the oxidation will be reduced as there will be a lower volume of effluent to be treated.

\subsubsection{Equilibrium of adsorption process}


The equilibrium of the adsorption process for the DCF removal using grape bagasse was evaluated applying the linearized equations of the Langmuir (Eq. 7) and Freundlich (Eq. 8) models [31]. The Sips isotherm, also known as the Langmuir-Freundlich, was also tested (Eq. 9) [19]:

$$
\begin{aligned}
& \frac{C_{e}}{q_{e}}=\frac{1}{q_{\max } \cdot K_{L}}+\frac{1}{q_{\max }} C_{e} \\
& \log q_{e}=\log K_{F}+\frac{1}{n} \log C_{e} \\
& q_{e}=\frac{q_{\max } \cdot K_{S} \cdot C_{e} 1 / n}{1+K_{S} \cdot C_{e}^{1 / n}}
\end{aligned}
$$

where $K_{\iota}\left(\mathrm{L} \mathrm{mg}^{-}\right), K_{r}\left(\mathrm{~L} \mathrm{~g}_{-}\right)$and $K_{s}\left(\mathrm{~L} \mathrm{mg}_{-}\right)$are the Langmuir, Freundlich and Sips constants, respectively; $q_{\max }(\mathrm{mg} \mathrm{g})$ is a parameter related to the maximum amount of adsorbate required for monolayer formation; and $n$ is a parameter related to the intensity of adsorption and to the system heterogeneity.

In order to identify the model that best describes the actual behavior of the adsorption equilibrium, besides the coefficient of determination, the error function $\left(\mathrm{F}_{\text {error }}\right)($ Eq. 10) was used, which compares point by point the experimental data with those obtained applying the model [19]:

$$
F_{\text {error }}=\sqrt{\frac{\sum_{i}^{p}\left(\frac{q_{i, m}-q_{i, \exp }}{q_{i, \exp }}\right)^{2}}{p}}
$$


where $q_{i, m}$ and $q_{i, \exp }$ represent the adsorption capacity obtained applying the theoretical model and the experimental data, respectively; and $p$ is the number of data points considered.

On comparing the three models tested (Table 4 and Figure 5) it was found that the Freundlich and Sips isotherms presented similar correlation coefficients (close to unity). However, in relation to the error function it was observed that the experimental data were well fitted by the Freundlich model. Thus, the adsorption process most likely occurs in more than one layer. Additionally, there was no saturation of the adsorbent, that is, the value of the adsorption capacity increased as the pharmaceutical concentration increased; however, the removal percentage remained at approximately $20 \%$. A value of $n$ greater than 1.0 indicated that the process of DCF adsorption onto the grape bagasse was favorable [36].

In terms of $K_{F}$, the adsorption capacity was compared with other studies and showed that the grape bagasse was more efficient with regard to the removal of DCF present in an aqueous medium than mesoporous silica [28]. In the case of grape bagasse, $1.0 \mathrm{~g}$ of this material allowed approximately $1.72 \mathrm{~L}$ of effluent to be treated, while the same mass of mesoporous silica SBA-15 could treat only $0.72 \mathrm{~L}$.

Although the adsorption capacity of the grape bagasse was lower than that of the granular activated carbon $\left(K_{F}=141 \mathrm{~g} \mathrm{~L}^{-1}\right.$ and $\left.n=0.19\right)$ [37], the DCF removal efficiency was very close to values reported in the literature (21-40\%) [6]. Furthermore, the time required for the system to reach equilibrium was much shorter using the grape bagasse as an adsorbent (maximum of 24 hours) compared to the granular activated carbon $(48 \mathrm{~h})[33,38]$. This verifies that the grape bagasse has potential to be used as an 
adsorbent of substances of pharmacological origin. In addition, the process of DCF adsorption onto grape bagasse was more efficient than other conventional wastewater treatments, such as biological filtration (removal of 9\%) [7] and coagulationflocculation processes (removal of less than 1\%) [39].

\subsubsection{Thermodynamics of the adsorption process}

The variation of Gibbs free energy $\left(\Delta G^{\circ}{ }_{a d s}\right)$ was estimated according to the following expression [31]: $\Delta G^{\circ}{ }_{a d s}=-R T \ln K$. The $K$ equilibrium constant, which represents the ratio between the concentration of solute that is adsorbed and the concentration of solute remaining in solution, can be calculated using the expression: $K=\left(C_{i}-C_{e}\right) / C_{e}$. According to Önal et al. [31], the variation of enthalpy $\left(\Delta H^{o}{ }_{a d s}\right)$ and entropy $\left(\Delta \mathrm{S}^{o}{ }_{a d s}\right)$ of adsorption can be estimated, respectively, from the angular and linear coefficients of the plot $\ln K$ versus $1 / \mathrm{T}$, i.e., the van't Hoff equation, which is expressed by Equation (11):

$$
\ln K=\frac{-\Delta H^{\circ}{ }_{a d s}}{R T}+\frac{\Delta S_{a d s}^{\circ}}{R}
$$

where $R$ is the universal gas constant $\left(8.314 \mathrm{~J} \mathrm{~mol}^{-1} \mathrm{~K}^{-1}\right)$, and $T$ is the absolute temperature $(\mathrm{K})$ of the system.

According to the results presented in Table 5, the increase in temperature caused a decrease in the amount of the pharmaceutical that was adsorbed onto the grape bagasse under equilibrium conditions. Similar results were obtained by Cuerda-Correa et al. [21] while assessing the effect of temperature on the adsorption of naproxen and ketoprofen 
by carbon black. These authors attributed the decrease in adsorption capacity to two factors: the solubility of the pharmaceuticals in water and the energy exchange that occurred during the process.

Thus, the temperature increase possibly caused an increase in the solubility of the DCF, which hindered its adsorption because the pharmaceutical would have more affinity with the solvent than with the adsorbent. The force of the attraction between the DCF and the grape bagasse decreased as a function of increasing temperature because the increasing temperature caused an increase in the agitation of the dissolved chemical species, reducing its interaction with the adsorbent.

Moreover, the adsorption process was exothermic, which confirmed the decrease in adsorption capacity with increasing temperature because as heat is released to the system, the equilibrium shifted to the opposite direction of the reaction. Additionally, the $\Delta H^{o}$ ads was less than $40 \mathrm{~kJ} \mathrm{~mol}^{-1}$, suggesting a physisorption process [31].

Concerning the change in free energy, the adsorption process of the DCF onto grape bagasse was not spontaneous, independent of temperature. Similar behavior was obtained by Özcan and Özcan [40], who evaluated the adsorption of acid dyes onto activated bentonite. According to these authors, positive values of $\Delta G^{\circ}$ ads indicated the presence of an energy barrier during the adsorption process. In the case of the adsorption of DCF, this energy barrier possibly originated due to the repulsion between the negative charges that were present both on the surface of the adsorbent and the DCF ion structures in the evaluated $\mathrm{pH}$ condition.

Additionally, the change in the $\Delta S^{\circ}$ ads of the process was negative, indicating that the randomness in the solid-solution interface decreased as DCF was adsorbed onto the 
grape bagasse [40]. This possibly occurred due to the formation of more than one layer of adsorption, which would organize the system and hence reduce the randomness. No thermodynamic data exist for the adsorption of DCF by other materials, which prevented us from making comparisons with other studies.

One of the few works in which the values of $\Delta G^{\circ}{ }_{a d s}, \Delta H^{\circ}$ ads and $\Delta S^{\circ}{ }_{a d s}$ were calculated for the adsorption of anti-inflammatory drugs was that published by Önal et al. [31], who evaluated the adsorption of naproxen by activated carbon that was produced from apricot waste. These authors observed an opposite behavior to that obtained in this study. In the case of naproxen adsorption by activated carbon, the process was spontaneous, endothermic and increased entropy.

\section{Conclusions}

The characterization results revealed that grape bagasse presents particles with heterogeneous shape and size with a macroporous structure, rich in hydroxyl groups. With respect to the adsorption process, the rate-controlling step was described using a pseudo-second-order kinetic model, and the adsorption isotherms were well fitted by the Freundlich model. Concerning the thermodynamic data, the results showed that the DCF adsorption occurred via an exothermic process accompanied by a decrease in the randomness at the solid/solution interface.

It can be concluded that the reuse of grape bagasse for the adsorption of pharmaceutical compounds has some advantages over granular activated carbon, such as insignificant commercial value, due to the fact that they are waste products of productive processes. This residue, having regionalized origin, can be used in wastewater treatment plants 
located in the same region, resulting in reduced transportation costs. Moreover, the generation of waste in the adsorption process is minimal, since the grape bagasse can be used as an adsorbent without prior chemical treatment and can be reused after desorption of the pharmaceutical compound. However, the practical application of grape bagasse as an adsorbent in a batch system should take into consideration the cost of drying the material and the mechanical stirring necessary for the homogenization of the system.

\section{Acknowledgements}

The authors thank the Waldemar Milani Winery for kindly providing the grape bagasse and the Fundação de Amparo à Pesquisa do Estado do Rio Grande do Sul (FAPERGS) for financial support. The careful suggestions of the reviewers were considerably helpful in improving the manuscript.

\section{References}

[1] C.G. Daughton, T.A. Ternes, Pharmaceuticals and personal care products in the environment: agents of subtle change? Environ. Health Persp. 107 (1999) 907-938. [2] K. Kümmerer, The presence of pharmaceuticals in the environment due to human use - present knowledge and future challenges, J. Environ. Manage. 90 (2009) 23542366.

[3] S. Mompelat, B. Le Bot, O. Thomas, Occurrence and fate of pharmaceutical products and by-products, from resource to drinking water, Environ. Int. 35 (2009) 803814. 
[4] L.H.M.L.M. Santos, A.N. Araújo, A. Fachini, A. Pena, C. Delerue-Matos, M.C.B.S.M. Montenegro, Ecotoxicological aspects related to the presence of pharmaceuticals in the aquatic environment, J. Hazard. Mater. 175 (2010) 45-95.

[5] A.C. Collier, Pharmaceutical contaminants in potable water: potential concerns for pregnant women and children, EcoHealth 4 (2007) 164-171.

[6] Y. Zhang, S. Geißen, C. Gal, Carbamazepine and diclofenac: removal in wastewater treatment plants and occurrence in water bodies, Chemosphere 73 (2008) 1151-1161.

[7] M. Stumpf, T.A. Ternes, R. Wilken, S.V. Rodrigues, W. Baumann, Polar drug residues in sewage and natural waters in the state of Rio de Janeiro, Brazil, Sci. Total Environ. 225 (1999) 135-141.

[8] J.L. Oaks, M. Gilbert, M.Z. Virani, R.T. Watson, C.U. Meteyer, B.A. Rideout, H.L. Shivaprasad, S. Ahmed, M.J.I. Chaudhry, M. Arshad, S. Mahmood, A. Ali, A.A. Khan, Diclofenac residues as the cause of vulture population decline in Pakistan, Nature, 427 (2004) 630-633.

[9] R. Triebskorn, H. Casper, A. Heyd, R. Eikemper, H.-R. Köhler, J. Schwaiger, Toxic effects of the non-steroidal anti-inflammatory drug diclofenac. Part II: citopatological effects in liver, kidney, gills and intestine of rainbow trout (Oncorhynchus mykiss), Aquat. Toxicol. 68 (2004) 151-166.

[10] E. Touraud, B. Roig, J. P. Sumpter, C. Coetsier, Drug residues and endocrine disruptors in drinking water: risk for humans? Int. J. Hyg. Environ. Health 214 (2011) $437-441$.

[11] S. Suárez, M. Carballa, F. Omil, J.M. Lema, How are pharmaceuticals and personal care products (PPCPs) removed from urban wastewaters? Rev. Environ. Sci.

Biotechnol. 7 (2008) 125-138. 
[12] R.W. Reis Filho, J.C. Barreiro, E.M. Vieira, Q.B. Cass, Fármacos, ETEs e corpos hídricos, Revista Ambi-Água 2 (2007) 54-61.

[13] A. Bhatnagar, M. Sillanpää, Utilization of agro-industrial and municipal waste materials as potential adsorbents for water treatment - A review, Chem. Eng. J. 157 (2010) 277-296.

[14] I. Villaescusa, N. Fiol, J. Poch, A. Bianchi, C. Bazzicalupi, Mechanism of paracetamol removal by vegetable wastes: the contribution of $\pi-\pi$ interactions, hydrogen bonding and hydrophobic effect, Desalination 270 (2011) 135-142.

[15] R.R. Northup, R.A. Dahlgren, J.G. McColl, Polyphenols as regulators of plantlitter-soil interactions in northern California's pygmy forest: a positive feedback? Biogeochemistry 42 (1998), pp. 189-220.

[16] K.S.W. Sing, D.H. Everett, R.A.W. Haul, L. Moscou, R.A. Pierotti, J. Rouquérol, T. Siemieniewska, Reporting physisorption data for gas/solid systems with special reference to the determination of surface area and porosity, Pure Appl. Chem. 57 (1985) 603-619.

[17] A.P. Sacco, Caracterização e estudo do comportamento térmico de ligninas extraídas de bagaço de cana-de-açúcar e dos resíduos sólidos urbanos. Tese de doutorado. UNESP, Araraquara, 2008.

[18] S.F. Montanher, Utilização da biomassa de bagaço de laranja como material sorvente de íons metálicos presentes em soluções aquosas. Tese de doutorado. UEM, Maringá, 2009.

[19] J.C.P. Vaghetti, Utilização de biossorventes para remediação de efluentes aquosos contaminados com íons metálicos. Tese de doutorado. UFRGS, Porto Alegre, 2009. 
[20] N.V. Farinella, G.D. Matos, E.L. Lehmann, M.A.Z. Arruda, Grape bagasse as an alternative natural adsorbent of cadmium and lead for effluent treatment, J. Hazard. Mater. 154 (2008) 1007-1012.

[21] E.M. Cuerda-Correa, J.R. Domínguez-Vargas, F.J. Olivares-Marín, J.B. de Heredia, On the use of carbon blacks as potencial low-cost adsorbents for the removal of non-steroidal anti-inflammatory drugs from river waters, J. Hazard. Mater. 177 (2010) 1046-1053.

[22] F.J. Beltrán, P. Pocostales, P. Alvarez, A. Oropesa, Diclofenac removal from water with ozone and activated carbon, J. Hazard. Mater. 163 (2009) 768-776.

[23] S.F. Montanher, E.A. Oliveira, M.C. Rollemberg, Removal of metal ions from aqueous solutions by sorption onto rice bran, J. Hazard. Mater. 117 (2005) 207-211. [24] S. Mohan, G. Sreelakshmi, Fixed bed column study for heavy metal removal using phosphate treated rice husk, J. Hazard. Mater. 153 (2008) 75-82.

[25] O. Ioannidou, A. Zabaniotou, Agricultural residues as precursors for activated carbon production - A review, Renew. Sust. Energ. Rev. 11 (2007) 1966-2005. [26] N.V. Farinella, G.D. Matos, M.A.Z. Arruda, Grape bagasse as a potencial biosorbent of metals in effluent treatments, Bioresource Technol. 98 (2007) 1940-1946. [27] B. Volesky, Biosorption and me, Water Res. 41 (2007) 4017-4029.

[28] T.X. Bui, H. Choi, Adsorptive removal of selected pharmaceuticals by mesoporous silica SBA-15, J. Hazard. Mater. 168 (2009) 602-608.

[29] S.K. Bajpai, M. Bhowmik, Adsorption of diclofenac sodium from aqueous solution using polyaniline as a potencial sorbent. I. Kinetic studies, J. Appl. Polym. Sci. 117 (2010) 3615-3622. 
[30] A. Rossner, S.A. Snyder, D.R.U. Knappe, Removal of emerging contaminants of concern by alternative adsorbents, Water Res. 43 (2009) 3787-3796.

[31] Y. Önal, C. Akmil-Başar, Ç. Sar1c1-Özdemir, Elucidation of the naproxen sodium adsorption onto activated carbon prepared from waste apricot: kinetic, equilibrium and thermodynamic characterization, J. Hazard. Mater. 148 (2007) 727-734.

[32] A.M.S. Mimura, T.V. de A. Vieira, P.B. Martelli, H. de F. Gorgulho, Aplicação da casca de arroz na adsorção dos íons $\mathrm{Cu}^{2+}, \mathrm{Al}^{3+}, \mathrm{Ni}^{2+}$ e $\mathrm{Zn}^{2+}$, Quím. Nova 33 (2010) $1279-1284$.

[33] B. Ruiz, I. Cabrita, A.S. Mestre, J.B. Parra, J. Pires, A.P. Carvalho, C.O. Ania, Surface heterogeneity effects of activated carbons on the kinetics of paracetamol removal from aqueous solution, Appl. Surf. Sci. 256 (2010) 5171-5175.

[34] H. Qiu, L. Lv, B. Pan, Q. Zhang, W. Zhang, Q. Zhang, Critical review in adsorption kinetic models, J. Zhejiang Univ. Sci. A 10 (2009) 716-724. [35] P.A.M. Mourão, P.J.M. Carrott, M.M.L.R. Carrott, Regeneração de carvões activados a partir de cortiça. In: Anais da XXXI Reunión Ibérica de Adsorción, 2006. Available at: <http://www.etseq.urv.es/lignocarb/seminars/peter7-tarragona.pdf>. [36] A.N. Fernandes, M. Giovanela, C.A.P. Almeida, V.I. Esteves, M.M.D. Sierra, M.T. Grassi, Remoção dos hormônios 17ß-estradiol e 17 $\alpha$-etinilestradiol de soluções aquosas empregando turfa decomposta como material adsorvente, Quím. Nova 34 (2011) 15261533.

[37] T.A. Ternes, M. Meisenheimer, D. Mcdowell, F. Sacher, H. Brauch, B. HaistGulde, G. Preuss, U. Wilme, N. Zulei-Seibert, Removal of pharmaceuticals during drinking water treatment, Environ. Sci. Technol. 36 (2002) 3855-3863. 
[38] D. Serrano, J.M. Lema, F. Omil, Influence of the employment of adsorption and coprecipitation agents for the removal of PPCPs in conventional activated sludge (CAS) systems, Water Sci. Technol. 62 (2010) 728-735.

[39] S.A. Snyder, E.C. Wert, H.D. Lei, P. Westerhoff, Y. Yoon, Removal of EDCs and pharmaceuticals in drinking and reuse treatment processes. Awwa Research Foundation, Denver, 2007.

[40] A.S. Özcan, A. Özcan, Adsorption of acid dyes from aqueous solutions onto acidactivated bentonite, J. Colloid Interf. Sci. 276 (2004) 39-46. 
Table 1. Integrated areas of the main peaks that were observed in the solid-state ${ }^{13} \mathrm{C}$ NMR spectrum of the grape bagasse.

\begin{tabular}{ccc}
\hline${\text { Chemical shift }(\mathbf{p p m})^{\mathbf{a}}}$ & Area (\%) & Assignments \\
\hline $0-47$ & 16.69 & Alkyl C \\
$47-60$ & 7.51 & Methoxyl \\
$60-95$ & 49.24 & O-alkyl C \\
$95-110$ & 10.33 & Ar-O-alkyl \\
$110-140$ & 7.95 & Promatic C \\
$140-165$ & 3.22 & Carboxyl C \\
$165-190$ & 4.59 & Carbonyl C \\
$190-215$ & 0.46 & \\
\hline
\end{tabular}

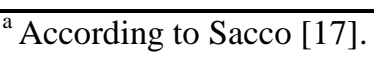


Table 2. Change in surface charge of grape bagasse as a function of $\mathrm{pH}$.

\begin{tabular}{cc}
\hline $\boldsymbol{p H}<\mathbf{3 . 5 9}$ & $\boldsymbol{p H}>\mathbf{3 . 5 9}$ \\
\hline $\mathrm{R}-\mathrm{COOH}_{(\mathrm{s})}+\mathrm{H}_{3} \mathrm{O}^{+}{ }_{(\mathrm{aq})} \leftrightarrow \mathrm{R}-\mathrm{COOH}_{2}^{+}{ }_{(\mathrm{s})}+\mathrm{H}_{2} \mathrm{O}_{(\mathrm{l})}$ & $\mathrm{R}-\mathrm{COOH}_{(\mathrm{s})}+\mathrm{OH}_{(\mathrm{aq})}^{-} \leftrightarrow \mathrm{R}-\mathrm{COO}_{(\mathrm{s})}^{-}+\mathrm{H}_{2} \mathrm{O}_{(\mathrm{l})}$ \\
$\mathrm{R}-\mathrm{OH}_{(\mathrm{s})}+\mathrm{H}_{3} \mathrm{O}_{(\text {aq) }}^{+} \leftrightarrow \mathrm{R}-\mathrm{OH}_{2}^{+}{ }_{(\mathrm{s})}+\mathrm{H}_{2} \mathrm{O}_{(\mathrm{l})}$ & $\mathrm{R}-\mathrm{OH}_{(\mathrm{s})}+\mathrm{OH}_{(\mathrm{aq})}^{-} \leftrightarrow \mathrm{R}-\mathrm{O}_{(\mathrm{s})}^{-}+\mathrm{H}_{2} \mathrm{O}_{(\mathrm{l})}$ \\
$\mathrm{R}-\mathrm{NH}_{2(\mathrm{~s})}+\mathrm{H}_{3} \mathrm{O}^{+}{ }_{(\mathrm{aq})} \leftrightarrow \mathrm{R}-\mathrm{NH}_{3}^{+}{ }_{(\mathrm{s})}+\mathrm{H}_{2} \mathrm{O}_{(\mathrm{l})}$ & $\mathrm{R}-\mathrm{NH}_{2(\mathrm{~s})}+\mathrm{OH}_{(\mathrm{aq})}^{-} \leftrightarrow \mathrm{R}-\mathrm{NH}_{(\mathrm{s})}^{-}+\mathrm{H}_{2} \mathrm{O}_{(\mathrm{l})}$ \\
\hline
\end{tabular}

Adsorption of anionic pharmaceuticals ${ }^{a} \quad$ Adsorption of cationic pharmaceuticals ${ }^{a}$

$\mathrm{R}=$ carbon chain; ${ }^{\mathrm{a}}$ Dependent on the $\mathrm{pK}_{\mathrm{a}}$ of the pharmaceutical. 
Table 3. Kinetic parameters for the adsorption of DCF onto grape bagasse.

\begin{tabular}{lccccc}
\hline $\begin{array}{l}\text { Concentration of DCF } \\
\left(\mathbf{m g ~ L} \mathbf{- 1}^{-1}\right)\end{array}$ & $\mathbf{5}$ & $\mathbf{1 0}$ & $\mathbf{1 5}$ & $\mathbf{2 0}$ & $\mathbf{3 0}$ \\
\hline $\mathrm{q}_{\mathrm{e}, \mathrm{exp}}\left(\mathrm{mg} \mathrm{g}^{-1}\right)$ & 5.12 & 11.06 & 12.73 & 18.75 & 23.77 \\
\hline Pseudo-second-order & & & & & \\
$\mathrm{q}_{\mathrm{e}}\left(\mathrm{mg} \mathrm{g}^{-1}\right)$ & 4.96 & 11.15 & 13.15 & 19.42 & 24.53 \\
$\mathrm{k}_{2} \times 10^{3}\left(\mathrm{~g} \mathrm{mg}^{-1} \mathrm{~min}^{-1}\right)$ & 11.28 & 2.10 & 16.21 & 9.28 & 6.65 \\
$\mathrm{~h}\left(\mathrm{mg} \mathrm{g}^{-1} \mathrm{~min}^{-1}\right)$ & 0.28 & 0.26 & 2.80 & 3.50 & 4.0 \\
$\mathrm{r}^{2}$ & 0.9961 & 0.9951 & 0.9948 & 0.9952 & 0.9960 \\
\hline Pseudo-first-order & & & & & \\
$\mathrm{q}_{\mathrm{e}}\left(\mathrm{mg} \mathrm{g}^{-1}\right)$ & 1.23 & 4.89 & 3.83 & 4.60 & 13.12 \\
$\mathrm{k}_{1} \times 10^{3}\left(\mathrm{~min}^{-1}\right)$ & 1.80 & 2.58 & 22.87 & 20.04 & 37.82 \\
$\mathrm{r}^{2}$ & 0.2882 & 0.7751 & 0.7808 & 0.3366 & 0.9106 \\
\hline
\end{tabular}


Table 4. Equilibrium parameters for the adsorption of DCF onto grape bagasse.

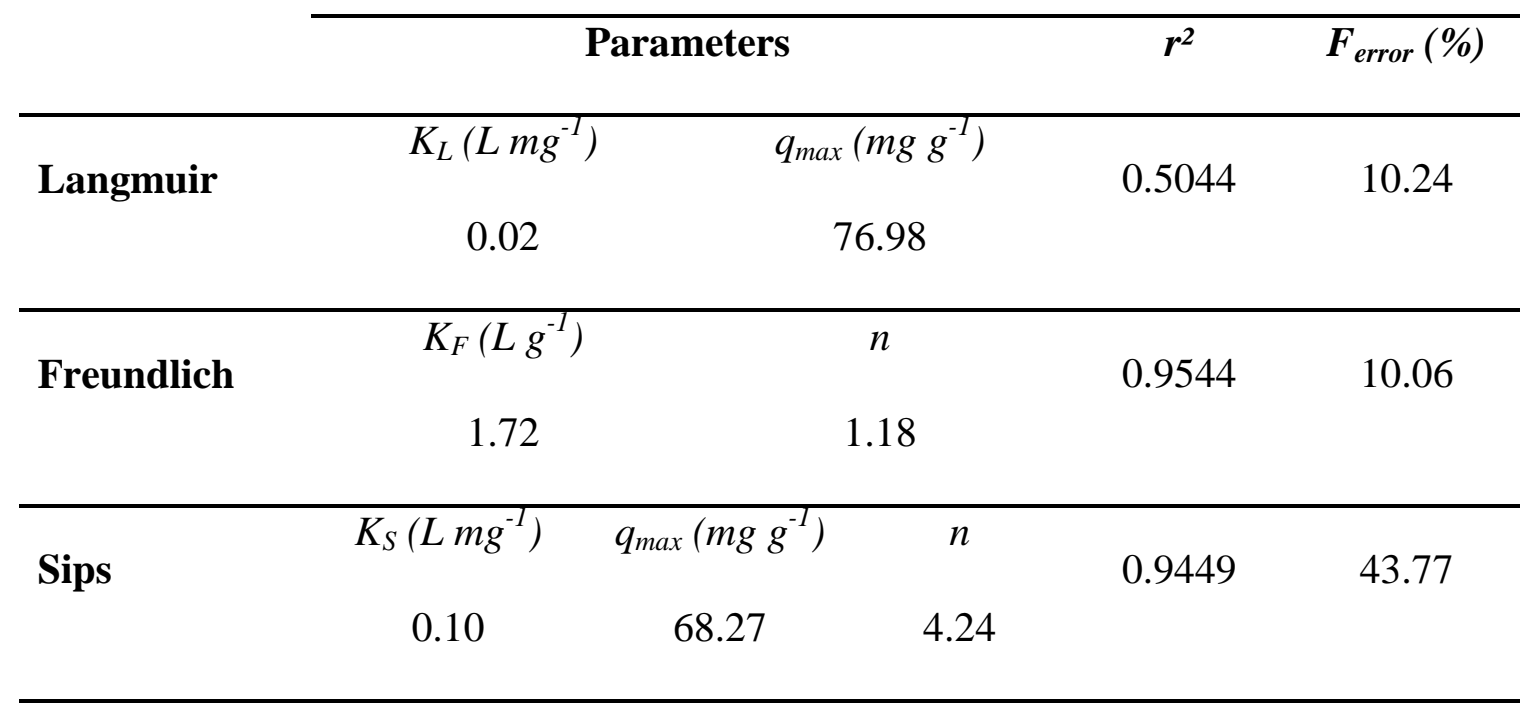


Table 5. Thermodynamic parameters for the adsorption of DCF onto grape bagasse at different temperatures at an initial concentration of DCF of $10 \mathrm{mg} \mathrm{L}^{-1}$.

\begin{tabular}{ccccccc}
\hline $\mathbf{T}$ & $\boldsymbol{q}_{e}$ & Removal & $\boldsymbol{\Delta}$ & $\begin{array}{c}\Delta \mathbf{G}^{\circ}{ }_{a d s} \\
\left(\mathbf{k J ~ m o l}^{\mathbf{- 1}}\right)\end{array}$ & $\begin{array}{c}\Delta \boldsymbol{H}^{\circ}{ }_{a d s} \\
\left(\mathbf{k J ~ m o l}^{\mathbf{- 1}}\right)\end{array}$ & $\begin{array}{c}\Delta \mathbf{S}^{\circ}{ }_{a d s} \\
\left(\mathbf{J ~ m o l}^{-\mathbf{1}} \mathbf{K}^{-\mathbf{1}}\right)\end{array}$ \\
\hline $\mathbf{2 2}$ & 11.15 & 22.80 & 0.30 & 2.99 & & \\
$\mathbf{3 0}$ & 6.92 & 14.02 & 0.16 & 4.57 & & -135.85 \\
$\mathbf{4 2}$ & 4.32 & 8.89 & 0.10 & 6.10 & & \\
$\mathbf{5 0}$ & 3.62 & 7.34 & 0.08 & 6.81 & & \\
\hline
\end{tabular}




\section{Figure Captions}

Figure 1. DCF structure.

Figure 2. Isotherms of adsorption/desorption of $\mathrm{N}_{2}$ by grape bagasse at $77 \mathrm{~K}$.

Figure 3. Adsorption capacity of DCF onto grape bagasse as a function of time.

Figure 4. Linear portions of the intraparticle diffusion model.

Figure 5. Isotherms of DCF adsorption onto grape bagasse at $22^{\circ} \mathrm{C}:(a)$ Langmuir model; (b) Freundlich model; (c) Sips model. 
Figure 1<smiles>COC(=O)Cc1ccccc1Nc1c(Cl)cccc1Cl</smiles> 
Figure 2

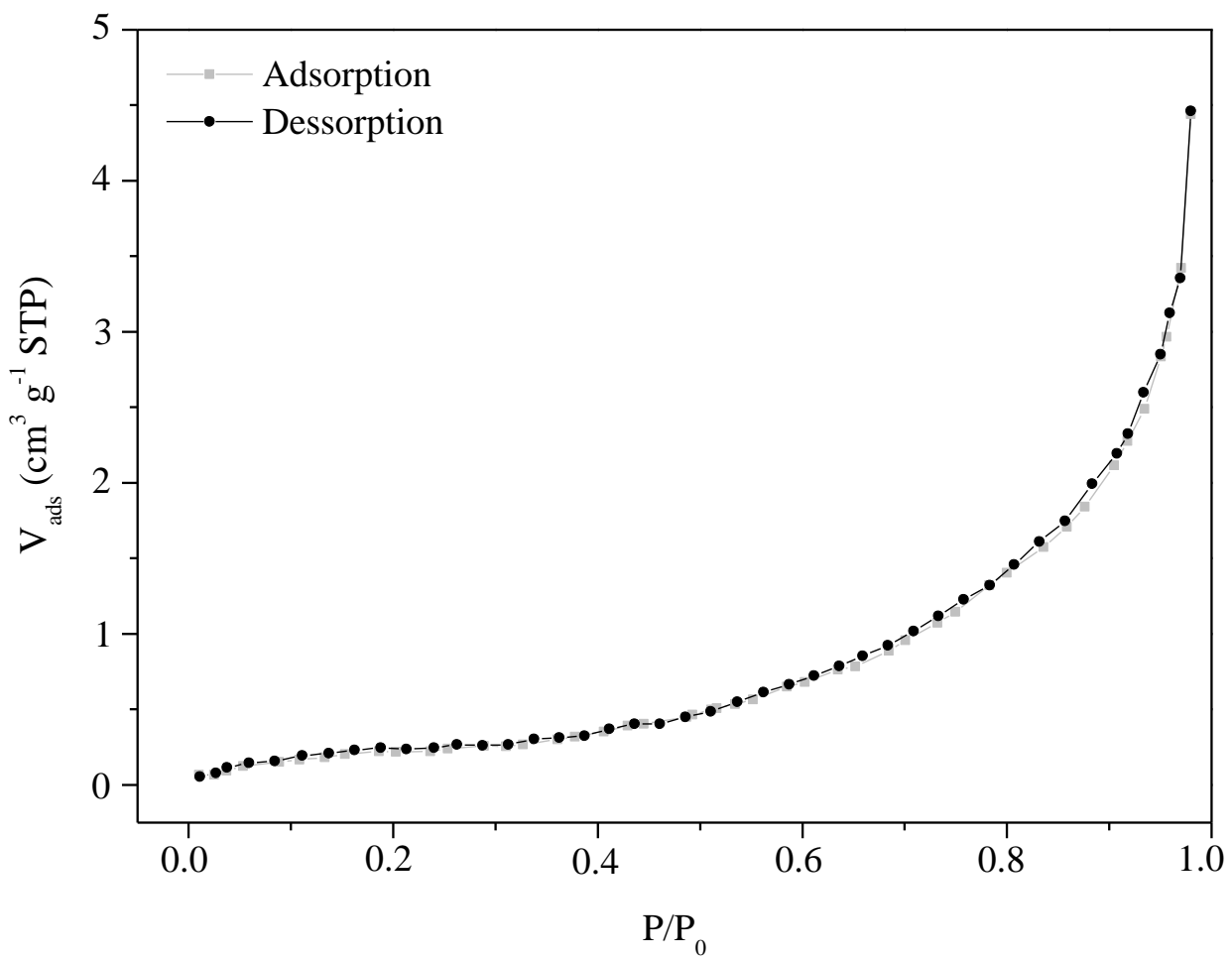


Figure 3
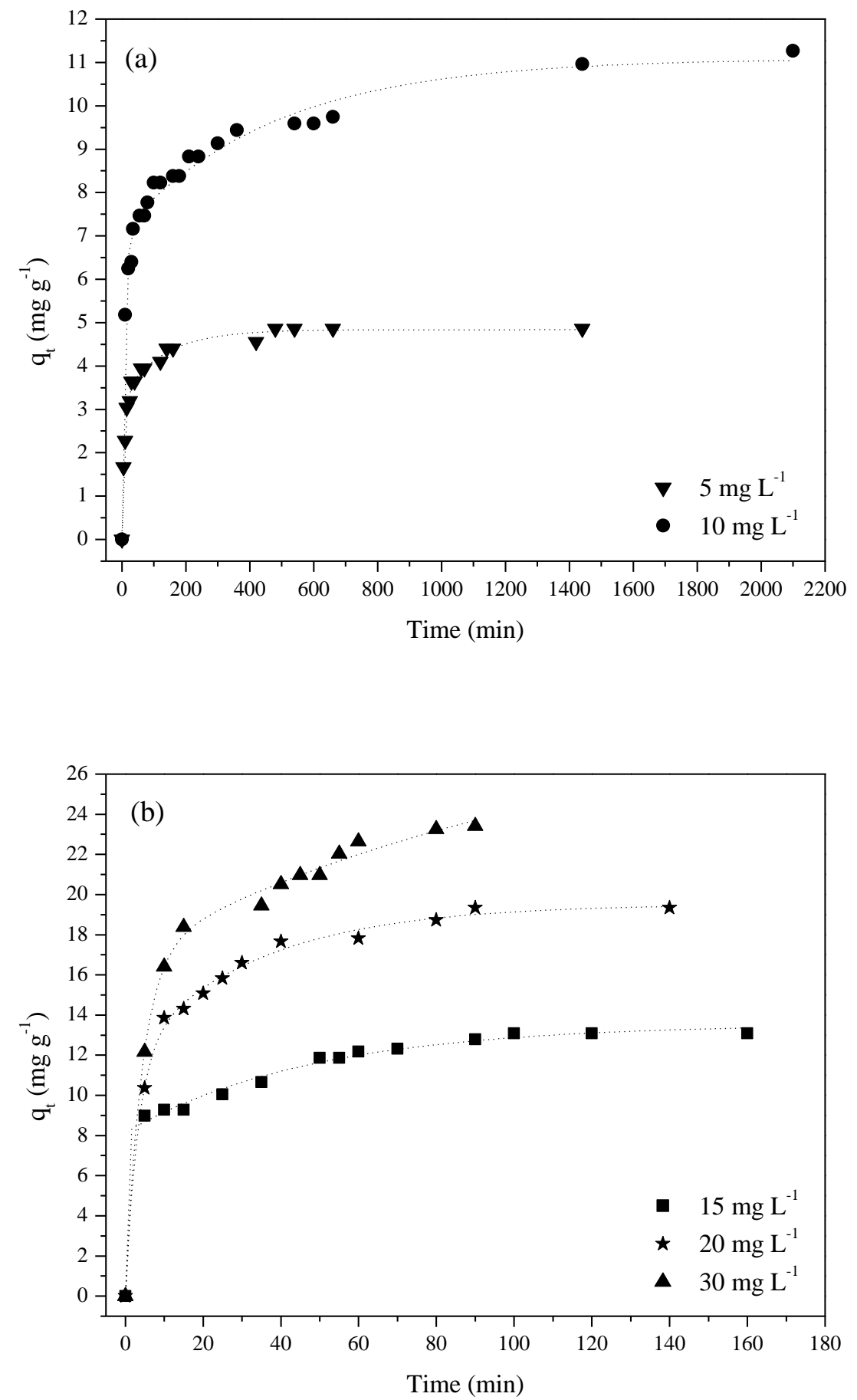
Figure 4

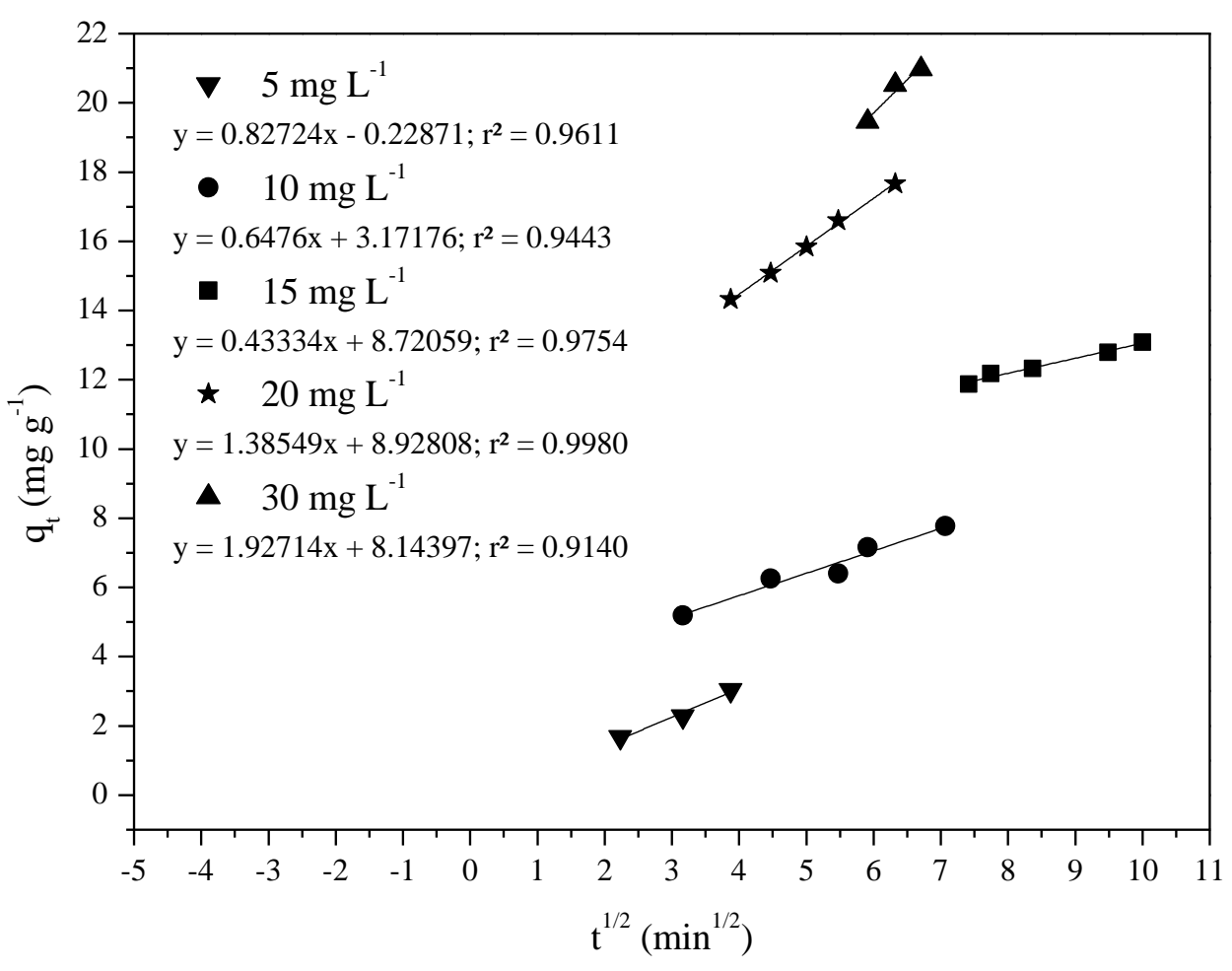


Figure 5
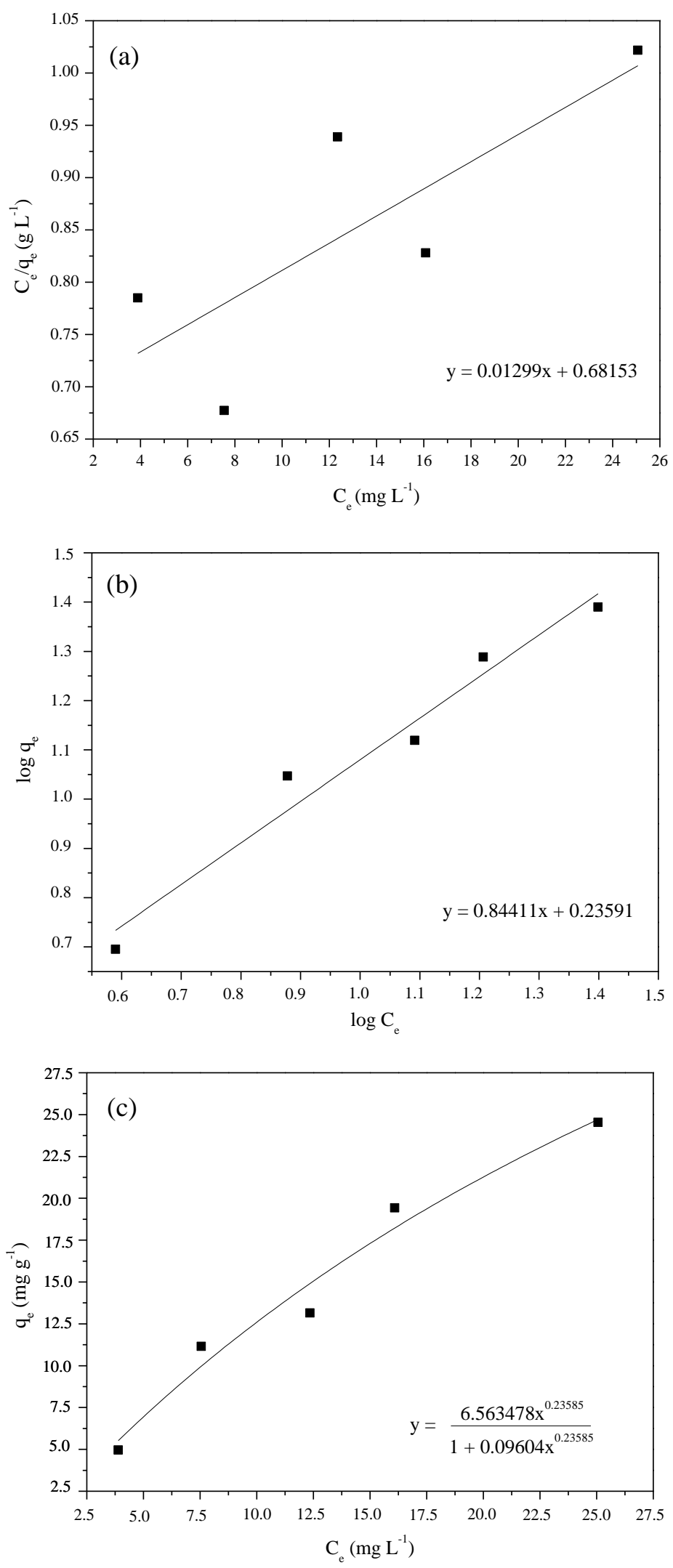